\title{
THE IMPACT OF WORKLIFE BALANCE FACTORS ON EMPLOYEE TURNOVER INTENTION THROUGH JOB SATISFACTION IN INSURANCE COMPANIES OF PAKISTAN
}

\author{
Anam Malik ${ }^{\mathrm{a}}$, Areebah Nadeem ${ }^{\mathrm{b}} *$ \\ a malikanam@hotmail.com, bareebah_nadeem@live.com, \\ ${ }^{\text {a }}$ COMSATS University Islamabad Campus, Pakistan
}

\begin{abstract}
A cross sectional study was designed to evaluate the impact of different work life balance factors on turnover intention through job satisfaction in different insurance companies in Pakistan. There are total 12 insurance companies in Pakistan, out of which four companies namely, State Life Insurance Corporation, EFU Life Assurance, JLI (Jubliee Life Insurance) and AdamJee Life Insurance Corporation located in Rawalpindi and Islamabad were selected. 300 questionnaires were distributed among the four insurance companies, of which 230 were returned, 19 were discarded, and hence a total sample size of 211 questionnaires was obtained. After data collection, the data was entered in SPSS 17 and the reliability of scales was tested using Cronbach Alpha's Coefficient Method. Correlation and regression analysis was performed for hypothesis testing. The results of the study showed that the primary factors that contribute to the work life balance are work place culture, social support, rewards and benefits, alternate working hours and recreation facilities. However, social support, alternate working hours and rewards and benefits had a significant positive relation with job satisfaction and negative relation with turnover intention. The finding of this study reported that the relationship between rewards and benefits and turnover intention were partially mediated by job satisfaction.
\end{abstract}

Keywords: Work life Balance Factors; Workplace Culture; Social Support; Rewards and Benefits; Alternate Working Hours; Recreation; Job Satisfaction; Turnover Intention.

\section{Introduction}

The fast pace economic and financial development around the globe has created many changes and endeavors for all the business organizations of the world. Globalization has turned the world into global village and has also evoked great changes in the organization culture. The role of family and work on the basis of gender was enforced in 20th century and it highlighted the important responsibilities of male and female employees. In the past, women were only considered to be responsible for household but this trend changed in the late 80's and then the family responsibilities became a hindrance to perform work effectively and efficiently, so it became crisis for the organizations and it also became impossible for the employees to keep a balance between work life and family (Hartmann, 2008). 
Work life balance (WLB) means the state of equilibrium in which demands of personal and job life are equal. Employees work very hard to maintain balance between their work and family life so that, they can accomplish the demands of the working life and to meet all the commitments and duties of family life. Those who fail to achieve this balance either leave the organization and therefore becoming less productive (Clark, 2007). In the current era, the modern organization systems are heading towards the more logical approach in dealing with their workers to satisfy them with their work and thereby reducing their intentions to leave the organization. This trend in organizations to make their workers satisfied is changing very quickly, by identifying several new factors and roles related with their life that just the hours they spend in their offices (Uma, 2010).

Work life balance is the preservation of a balance between roles and responsibilities at home and work. The employees view regarding the benefits of working conditions that they provide to help employees to balance the work and family domains as work life benefits (Rusell \& Bowman, 2011).

Job satisfaction can become a part of life satisfaction only if employees are able to maintain a balance in their work and family life. It can be referred as the feeling, which a worker has towards his job and which has both emotional and rational elements. The employee's job satisfaction is affected because of many factors such as promotions, salary, age, and opportunity for advancement, experiences, working conditions, supervision and employee's goal setting (Uma, 2010).

Employee retention is the most important target of every organization because sometimes the high salaries and better positions are just not enough for them to stay in the organization but also there are some other factors that help to retain them like workplace culture, social support, rewards and benefits, working hours, recreation and job satisfaction.

\section{Statement of the Problem}

The current global economy is very complex that demands productivity and high efficiency from the employees. This high pressure and complexity has lead to a reduction in employees work life balance which in turn has lead to a reduction in job satisfaction and an increase in turnover intention. There was also a time when boundaries between work and family were clear. Today maintaining work life balance is not a simple task and work is likely to occupy our personal life. The new trends in the workplace have been developing tension, responsibilities to the family, work related pressures, lack of social support and insufficient rewards and benefits makes an individual's life difficult to find a balance between work and family life. The job satisfaction of the workers affects the organization's performance because it provides positive behaviors of the workers. Retaining employees at any cost is very important because business is largely affected due to turnover.

Insurance companies are one of the rising sectors now where long working hours and increase work load are common practices. The employees are more involved with public dealings and convincing clients, which is a tough job. In this scenario, the most important factor that affects the behaviors of the workers in the organizations is the feeling of working satisfaction, which is job satisfaction which ultimately leads towards retention. Every organization should give high priority to keep their employees satisfied by providing several facilities such as by providing rewards and benefits and better working conditions which improves satisfaction, reduces turnover and helps in attaining work life balance. Many studies have been demonstrated on work life balance, job satisfaction and turnover intention of employees. Different factors like workplace 
culture, social support, rewards and benefits, working hours and others have been right through studies. However, little emphasize has been put to examine the role of work life balance to turnover intention through job satisfaction. Therefore, this research in purposed to examine the relationship between work life balances factors on turnover intention through job satisfaction in different insurance companies of Pakistan.

\section{Objectives of the Study}

The purpose of this study was to explore and analyze the factors related with work life balance that affect the turnover intention of employees through job satisfaction in Pakistan. This study contributed towards the biggest challenge of an organization that is the employee job satisfaction and turnover intention, which is a very important and crucial part of human resource management. Thus, the objectives of this study are:

- To identify different work-life balance factors affecting employee turnover intention through job satisfaction in different insurance companies.

- To analyze the impact of factors associated with the work-life balance on turnover intention through job satisfaction among the employees in insurance companies and private organizations of Pakistan and to analyze the relationship of such factors that affect employee retention.

\section{Significance of the study}

Work -life balance in the current era is of great value because today's current working environment characterized by high rate of labor market, women participation, longer working hours, latest technology, competitive market and the most important one is the renewed interest in family values and personal life. Employees leave organizations because a lot of reasons and balancing work and family life along with job satisfaction can be the most important reason as compared to others. So, the main aim of this study is to analyze and discuss the new emerging factors of work life balance that can decrease the employee turnover intention with the help of job satisfaction so that the turnover intention among Pakistani employees would be controlled.

Retaining employees in the current business environment is of great importance because in today's modern world, the technology is changing rapidly and there is very tough market competition as well. So, keeping that in mind, the significance of this study can be stated as follows:

- The research can be helpful for the organizations to find out the role of the corporate culture in providing the work life balance and helping in satisfaction of the employees and reducing their turnover intention.

- The research can be helpful for insurance companies to identify the factors which influence the employee work-life balance and the job satisfaction.

- The findings of this study can be useful for the organization to formulate family friendly policies, thus helping the organizations to enhance effectiveness, productivity and retaining the valuable employees.

\section{Literature Review}

The work life balance could be defined as the ability to make choices that satisfies one purpose over the period of time (Claiborne, 2009). The challenging and frustrating search for work-life balance is a very common between men and women and the frequent topic of conversation which is usually not translated into enough support or time to do, to manage and to handle our personal responsibilities and work commitments. In the society which is filled with conflicting commitments and responsibilities, work-life balance has become 
a key issue in the organization (Lockwood, 2003). The three main things which are very important to maintain balance between work and family life include understanding time, choice and purpose. Therefore, achieving a balance between work and family life it's necessary that one should be happy and satisfied (Buildings, 2005).

Noor (2011) stated that the work-life balance is about the act of maintaining balance between the work and other activities that are very important to people such as family, career or personal development, and recreation.

\subsection{Work Life Balance Factors}

Work life balance (WLB) plays a crucial role in reducing the dissatisfaction of jobs among the employees. Different organizations provide different WLB opportunities to employees so that they manage their work and family life activities very comfortably (Eikhof et al., 2007). If organizations provide different fringe benefits, rewards, flexi-timings and recreation activities then it can leads to increased employees job satisfaction and reduction in turnover (Santhi \& Sundar, 2012). Many organizations introduced different family friendly policies to answer the problems related with employee's retention. These practices of work life balance leads to descending trends in turnover and job dissatisfaction. Some researchers highlighted the effect of different family friendly policies on turnover intention of employees. Employees who had access to achieve work life balance showed significantly great organizational commitment and significantly low intention to leave their jobs (Grover \& Crooker, 2005). In order to have a better understanding that which component of work life balance factors affected turnover intention and job satisfaction. The five main components below are tested individually includes:

- Workplace Culture

- Social Support

- Rewards and Benefits

- Alternate Working Hours

- Recreation

\subsubsection{Workplace Culture}

The overtime and heavy workloads does not seem to cause the excess stress and drive the talents away, but further development of different work-life balance policies for the employees can benefit both the employees and employers. The emphasis on employee's work-life balance will provide a viable advantage for the companies in their mission to attract and retain the talents. In their attempt to improve their employee's worklife balance and make themselves as an "employer of choice", companies should attentively take into consideration the existing cultural differences among them.

Many studies have examined that workplace culture generally focus on the different attitudinal responses towards the organizational policies and structures from the both employees and employers perspective and the management culture. The most common issues and problems include the attitudes of an organization towards the working employees, which might influence the decision-making process of whether to work in that organization, or not (Malik et al., 2010). Lourel et al. (2008) investigated the significance of work-family life in their research and discussed how they are related to job satisfaction. It was revealed that work-life is a very critical issue and the employee's commitment is very high in the organizations that includes work life balance policies and showed that workplace culture is big supporter of work-family balance and the support from management towards employees is also fundamental for their commitments the organization. 


\subsubsection{Social Support}

According to a study by Perlow (2005) the social support provided by friends and family might have a positive influence on work-life balance and reducing the work-family conflict. The limitations between family and work are very vital to consider the relation between social support with the work-family balance and the outcomes related with work. It was suggested by Allen (2011) that social support in any organization such as the support from colleagues and supervisors has a positive impact on the job satisfaction. The social support related to work comes from supervisors and peers, where an employee works. Whereas the personal social support comes from parents, spouse, children, friends and family (Malik et al., 2010). Valcour et al. (2011) revealed that the workers perceptions of organizations work-life support was influenced mainly by signaling that the organization cares about their work and family life and helping them develop the resources they need to integrate between their work and life roles.

\subsubsection{Rewards and Benefits}

In business environment, rewards can be in several forms. It includes different recognition awards, increments in salary, bonuses etc. It is very important that the rewards should leave a lasting impression on employee because it will make a confirmation to the employees that they are valued and appreciated (Silbert, 2005). Dockel et al. (2006) described that organizations should accommodate employees by providing remote access for childcare centers, telecommuting, and employee assistance and referral programs. This will result in having positive influences among employees' attachment towards the organization and then only employees will have more positive attitude towards their organizations.

There is no proper definition of what basically constitutes work-life balance practice, this term usually refers to one of the following either it can be organizational support, family leave or flexible work options. The main focus of work life balance is based upon the stress-free and flexible working environment by making provisions for all the childcare facilities and the access to the families (Silbert, 2005).

\subsubsection{Alternate Working Hours}

Clark (2007) defined that balance as "the satisfaction and good functioning at work and home with minimum role conflict" and new trends like tele-working addressed the work-family issues. Tele-working can lead towards the great independence and independence, and it can also make the people to work for long period of time, including evenings and weekends helping the employees to manage their work and family life. An Australian study by (Eikhof et al., 2007) revealed that, the only thing that can affect one's life, more than the working hours is job satisfaction.

Hence all work life balance practices usually includes flexible working hours (e.g. flextime, which allows workers to differ their start and finishing times provided with number of hours worked and working from home (tele-work), family leave programs like adoption leave, parental leave and compassionate leave), on-site childcare, sharing the full time job between the two employees (job sharing), and financial assistance with elder and child care services (Malik et al.,2010). 


\subsubsection{Recreation}

Perlow (2005) suggested that an additional element known, as 'recreational labor' is required to be more reflective of the current issues which individuals usually face when they balance their work and life. The article intended to emphasize the number of ways in which the concept of work-life balance was narrowly deployed. The third element 'recreation labor' refers to the area of leisure, enjoyment and pleasure reflecting towards the aspirations that adults wished to achieve once essential tasks (paid and unpaid) have been fulfilled. The recreational activities can often be related with 'work' activities for example, going out with colleagues for a meal and may also overlap with 'family life' for example, playing with their children etc. The incorporation of recreation services with the employees experience has led to an increase in importance of recreation programming in different companies. The previous research highlights that the different sport facilities and recreational programs act as recruiting enhancements, which increase the satisfaction with naive experience and make a positive contribution to organization's retention efforts (Lindsey \& Sessoms, 2006).

\subsection{Job Satisfaction}

Job satisfaction has different definitions and perspectives by everyone. It was revealed by Williams et al. (2003) that the job satisfaction analyzes good relationship with colleagues and staff. The previous studies found that job satisfaction is related with rewards, benefits, empowerment, different achievements, the working conditions and good relations with others. The previous studies found that job satisfaction is related with salary, stress, company, relationship with others, personal growth, achievement and the overall working environment. It has been argued that an increase in job satisfaction increases worker productivity (Shikdar \& Das, 2003).

Shaffer (2011) revealed that the job satisfaction is related with the extent to which one's needs associated with work are satisfied. Individuals, who are happy with their job, are more usually likely to have an experienced satisfaction. According to Kuo and Chen (2004) the significant differences were found such as overall job satisfaction with regard to age, marital status, position and salary. In determining the different levels of job satisfaction among the employees, it was observed that when the employee is getting autonomy in the decision making, then they will have high job satisfaction level and low job stress as compared to other workers.

\subsection{Turnover Intention}

It was suggested that the relation between the different family friendly policies and turnover intention is related directly. Spector (2007) identified the close relation between the job satisfaction, organizational commitment and reduced turnover, and also investigated the clear influence that job satisfaction had on the turnover intentions among the engineering staff. The policies made by the organization to handle different work life conflict are commonly known as "work life policies". These work life policies have a significant and positive impact on employee's job satisfaction, and also reduces the turnover intention among them.

Turnover intention of useful employees decreases the organizational commitment but increases the extra cost of the company's expense to train the new employees that act as replacement of the other employees Grover and Crooker (2005). According to Lambert (2011), it was found that the high job satisfaction is connected with low employee turnover. The research also shows that the relation between the actual employee turnover 
and job satisfaction is moderated by the intentions. Silverthorne (2008) identified that better the, the higher will be the job satisfaction, organizational commitment and the lower turnover rate of employees if they better fit within the organization.

\subsection{Job Satisfaction and Turnover Intention}

The previous studies demonstrated that job satisfaction of employees and their commitment are predictors of turnover (Silverthrone, 2008). Besides, Schwepker (2005) showed the relationship between the organizational commitment, reduction in turnover intention and job satisfaction, and verified the clear effect of job satisfaction on the employee's turnover intentions. Spector (2007) also demonstrated the relationship between turnover intentions of employees and job satisfaction.

\section{Research Methodology}

The main purpose of this study was to identify the factors related to work life balance that affect the employee turnover intention through job satisfaction in insurance companies of Pakistan. For this purpose, a cross sectional study was designed to evaluate the responses of the employees belonging to different insurance companies. The primary data collection method was used in this research and data was collected through questionnaires. The sampling technique used was the convenient sampling and the unit of analysis was the employees working in insurance organizations of Pakistan. The population for the present study includes employees from the insurance companies of Pakistan. There are total 12 insurance companies in Pakistan, out of which 4 were selected that includes State Life Insurance Corporation, EFU Life Assurance, JLI (Jubliee Life Insurance) and AdamJee Life Insurance Corporation respectively. The twin cities Islamabad and Rawalpindi were chosen for this study because of limited time and resources. There are approximately total 30 offices of each insurance company in both cities out of which four are selected from Rawalpindi and Islamabad where approximately 1500 employees work. For this study, the sample size was drawn according to the formula ( $\mathrm{N}: 50+8 \mathrm{~m}$, where $\mathrm{m}=$ no of independent variables), this formula was used by Tabachnick and Fidell (2011) to calculate the sample size. As there were five independent variables used in this research, therefore the estimated sample size is 96 . So accordingly, 300 questionnaires were distributed in the four insurance companies located in Islamabad and Rawalpindi from which 230 were returned out of which 19 were discarded and a sample size of 211 questionnaires was obtained.

\section{Hypothesis}

According to this study which investigates the work life balance factors impacting employee turnover intention through job satisfaction in Insurance Companies of Pakistan, following hypothesis were proposed:

H1a: There is a significant relationship between workplace culture and job satisfaction

H1b: There is a significant relationship between workplace culture and turnover intention

H2a: There is a significant relationship between social support and job satisfaction.

H2b: There is a significant relationship between social support and turnover intention.

H3a: There is a significant relationship between rewards and benefits and job satisfaction. 
$\mathrm{H} 3 \mathrm{~b}$ : There is a significant relationship between rewards and benefits and turnover intention.

H4a: There is no significant relationship between alternate working hours and job satisfaction.

$\mathrm{H} 4 \mathrm{~b}$ : There is a significant relationship between alternate working hours and turnover intention.

H5a There is a significant relationship between recreation and job satisfaction.

H5b: There is a significant relationship between recreation and turnover intention.

H6: There is a significant relationship between job satisfaction and turnover intention.

H7: The job satisfaction mediates the relationship between work life balance factors and turnover intention.

\section{Result and Discussion}

The demographic characteristics of the respondents show that. $82.1 \%$ of the respondents are male and $18.9 \%$ are females and the percentage of females is less because there are less females working in this sector in Pakistan. Similarly, $10 \%$ respondents of sample belongs to age group of 20-29 while 64.9\% belongs to 30-39, $22.3 \%$ belongs to $40-49$ and $2.8 \%$ belongs to 50 onwards group. Moreover $16.6 \%$ of respondents belonged to top level management, $72 \%$ to middle level management and $11.4 \%$ to low level management. $90.5 \%$ of employees were married and $9.5 \%$ were not married and $60.2 \%$ of employees have experience from 6-8 years, $10.9 \%$ from 8 years or above, $20.4 \%$ from $3-5 y e a r s, 3.3 \%$ from $1-2$ years and $5.2 \%$ less than one year. The descriptive statistics are shown in Table 1.

Table1. Descriptive Statistics of Variable

\begin{tabular}{lll}
\hline Variables & Mean & $\begin{array}{l}\text { Standard } \\
\text { Deviation }\end{array}$ \\
\hline Workplace Culture & 3.312 & 0.26 \\
Social Support & 3.190 & 0.27 \\
Rewards \& Benefits & 3.380 & 0.38 \\
Alternate Working Hours & 2.338 & 0.22 \\
Recreation & 3.284 & 0.35 \\
Job Satisfaction & 3.487 & 0.26 \\
Turnover Intention & 2.370 & 0.63 \\
\end{tabular}

\subsection{Reliability and Validity}

Cronbach's Alpha is applied in the study to determine the reliability of the data. There were total 37 items in the questionnaire and the Cronbach's alpha values of items were found to be 0.724 that lies within the acceptable range Content validity assures that the data set has sufficient and adequate quantity of items that 
would work alongside the concept (Sekaran, 2009). Workplace Culture, Social Support, Rewards and Benefits, Alternate Working Hours, Recreation (independent variables), Job Satisfaction (mediating variable) and Turnover Intention (dependent variable) sig (p-value) value is 0.000 , therefore, these variables satisfy the validity test.

\subsection{Correlation Analysis}

The value of independent variable workplace culture and job satisfaction is $r=.239(\mathrm{p}<0.01)$. This coefficient shows that there is a positive relationship between work place culture and the job satisfaction and there is also a significant relation between workplace culture and job satisfaction and it is concluded that workplace culture has an impact on the employees job satisfaction and also has a positive relation, so insurance company can increase employees job satisfaction if they have positive workplace culture in the organization. Similarly, the correlation between the social support and job satisfaction is $r=.164(p<0.05)$.

This coefficient shows that there is a positive relationship between the social support and the job satisfaction. So, there is a significant relation between social support and job satisfaction and it is concluded that as social support has an impact on the level of employee, job satisfaction in insurance sector and also has a positive relation so insurance company can increase employee, job satisfaction if the social support system is increased in the organization. Whereas the correlation between the rewards and benefits and job satisfaction is $r=.283$, ( $\mathrm{p}<0.01$ ). This coefficient shows that there is a positive relationship between the rewards and benefits and job satisfaction. So, there is significant relation between rewards and benefits and job satisfaction and it is concluded that rewards and benefits has an impact on the level of employee job satisfaction in insurance companies and have a positive relation, so if more rewards and benefits are offered in the organization then the level of job satisfaction could be increased among the employees.

The correlation between the alternate working hours and job satisfaction is $\mathrm{r}=.118$, $(\mathrm{p}<0.01)$. This coefficient shows that there is a positive relationship between the alternate working hours and the job satisfaction. It also shows that there is a significant relation between alternate working hours and job satisfaction and it is concluded that alternate working hours have an impact on the level of employee\&\#39;s job satisfaction and also has a positive relation. So, insurance companies can increase employee job satisfaction if some more alternate working hour options are given to employees. Similarly, the correlation between the recreation and job satisfaction is $r=.163(\mathrm{p}<0.01)$. This coefficient shows that there is a positive relationship between the recreation and the job satisfaction. So, there is a significant relation between recreation and job satisfaction and it is concluded that recreation has an impact on the level of employee\&\#39;s job satisfaction in insurance sector and has a positive relation so insurance company can increase the employee job satisfaction, if the recreation facilities are provided in the organization.

The correlation between the turnover intention and job satisfaction is $r=-.437(\mathrm{p}<0.01)$. This coefficient shows that there is a negative relationship between the job satisfaction and turnover intention. It has a negative relation so turnover intention of employees can be reduced if the job satisfaction level of employees is increased. More over the other work life balance factors like workplace culture, social support, rewards and benefits, alternate working hours and recreation have negative correlation with turnover intention and also have significant relation between them except for recreation. Workplace culture $(\mathrm{r}=-.118, \mathrm{p}<0.05)$, social support $(\mathrm{r}=-.122, \mathrm{p}<0.01)$, rewards and benefits $(\mathrm{r}=-.358, \mathrm{p}<0.01)$, alternate working hours $(\mathrm{r}=-.159, \mathrm{p}<$ $0.01)$, recreation $(\mathrm{r}=-.058, \mathrm{p}<0.05)$ respectively. 


\begin{tabular}{lll}
\hline Variables & $\begin{array}{l}\text { Pearson } \\
\text { Correlation with } \\
\text { Retention (r) }\end{array}$ & P-value \\
\hline Workplace Culture & .239 & .001 \\
Social Support & .164 & .017 \\
Rewards \& Benefits & .238 & .000 \\
Alternate Working Hours & .118 & .014 \\
Recreation & .163 & .018 \\
\hline
\end{tabular}

Table3. Correlation between Independent Variables and Turnover Intention

\begin{tabular}{lll}
\hline Variables & $\begin{array}{l}\text { Pearson } \\
\text { Correlation with } \\
\text { Retention (r) }\end{array}$ & P-value \\
& -.118 & .001 \\
\hline Workplace Culture & -.122 & .017 \\
Social Support & -.358 & .000 \\
Rewards \& Benefits & -.159 & .003 \\
Alternate Working Hours & -.158 & .297 \\
Recreation & & \\
\hline
\end{tabular}

Table4. Correlation between Job Satisfaction and Turnover Intention

\begin{tabular}{lll}
\hline Variables & $\begin{array}{l}\text { Pearson } \\
\text { Correlation with } \\
\text { Retention (r) }\end{array}$ & P-value \\
& -.437 & .001
\end{tabular}

\subsection{Regression Analysis And Hypothesis Testing}

After satisfying all the assumptions of regression analysis, we can apply the multiple regressions on the data. It was mentioned previously that work life balance factors are the main independent variables, job satisfaction is the mediating variable and turnover intention is the main dependent variable. Baron and Kenny (1986) equations is used see the mediating effect of job satisfaction between work life balance factors and turnover intention. For this purpose, four separate regression analysis were conducted in order to test the mediating effect of job satisfaction between turnover intention and work life balance factors which are given below

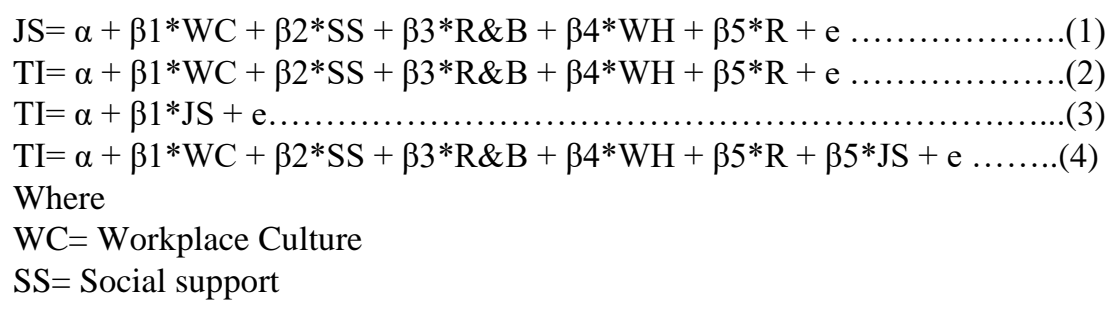


$\mathrm{R} \& \mathrm{~B}=$ Rewards and Benefits

$\mathrm{WH}=$ Working hours

$\mathrm{R}=$ Recreation

$\mathrm{JS}=$ Job Satisfaction

$\mathrm{TI}=$ Turnover Intention

$\alpha=$ Intercept

$\mathrm{e}=$ error term

The equation 1 examines the impact of the independent variables on the mediating variable. The job satisfaction was regressed on the independent variables i-e wok life balance factors including workplace culture, social support, rewards and benefits, alternate working hours and recreation. The results revealed that workplace culture has a value (beta $=.270, \mathrm{p}<0.01$ ) which shows that it is related with job satisfaction and has a positive and significant relation that shows the hypothesis (H1a) is accepted. Similarly, social support (beta $=.053, \mathrm{p}<0.05$ ) which shows that social support is related with job satisfaction and has a positive and significant relation that accepted the hypothesis $(\mathrm{H} 2 \mathrm{a})$. Similarly rewards and benefits (beta $=.176, \mathrm{p}<0.01$ ) which indicates that they are positively related with job satisfaction and have significant relation that accepted the hypothesis $(\mathrm{H} 3 \mathrm{a})$, alternate working hours (beta $=.145, \mathrm{p}<0.05)$ which indicates that they have a positive and significant relation that accepted hypothesis $(\mathrm{H} 4 \mathrm{a})$ and recreation (beta $=.427, \mathrm{p}<0.05)$ which indicates that recreation has a positive and significant relation with job satisfaction that accepted the null hypothesis (H5a) The R2 of the model is 0.213 which shows that approximately $21.3 \%$ of variance in the dependent variable is explained by the linear combination of independent variables that includes workplace culture, social support, rewards and benefits, alternate working hours and recreation among the employees in insurance companies. The model is also significant with F-value of 10.156 as shown in Table 5.

Table5. Results -Dependent Variable: Job Satisfaction

\begin{tabular}{lll}
\hline Variables & Co-efficient $(\beta)$ & P-value \\
\hline Constant & 9.935 & \\
Workplace Culture & .270 & .003 \\
Social Support & .053 & .035 \\
Rewards \& Benefits & .176 & .000 \\
Alternate Working Hours & .145 & .017 \\
Recreation & .427 & .013 \\
F & 10.156 & .000 \\
R-square & .213 &
\end{tabular}

The equation 2 explores the impact of the independent variables on dependent variable. Work life Balance factors including workplace culture (beta $=-.147, \mathrm{p}>0.05$ ) was negatively and insignificantly related with turnover intention that rejected the hypothesis $(\mathrm{H} 1 \mathrm{a})$, alternate working hours (beta $=-.128, \mathrm{p}<0.05$ ) are negatively but significantly related to turnover intention that accepted the hypothesis (H4b). Social support (beta $=-.095, \mathrm{p}<0.05)$ was negatively but significantly related with turnover intention that accepted the $(\mathrm{H} 2 \mathrm{~b})$. Similarly, rewards and benefits (beta $=-.167, \mathrm{p}<0.01$ ) were negatively and significantly related with turnover intention that accepted the hypothesis $(\mathrm{H} 3 \mathrm{~b})$. Recreation (beta $=-.187, \mathrm{p}>0.05$ ) was negatively and insignificantly related with turnover intention that rejected the hypothesis (H5b). The R2 of the model is 0.251 
which shows that approximately $25.1 \%$ of variance in the dependent variable that is turnover intention is explained by the linear combination of independent variables that includes workplace culture, social support, rewards and benefits, alternate working hours and recreation among the employees in insurance companies. The model is also significant with F-value of 9.259 as shown in Table 6.

Table6. Results -Dependent Variable: Turnover Intention

\begin{tabular}{lll}
\hline Variables & Co-efficient $(\beta)$ & P-value \\
\hline Constant & 15.057 & \\
Workplace Culture & -.147 & .134 \\
Social Support & -.095 & .020 \\
Rewards \& Benefits & -.167 & .001 \\
Alternate Working Hours & -.128 & .026 \\
Recreation & -.187 & .305 \\
F & 9.295 & .000 \\
R-square & .251 & \\
& & \\
\hline
\end{tabular}

The equation 3 explores the effect of mediating variable on dependent variable. It was found that job satisfaction (beta $=-.452, \mathrm{p}<0.05$ ) was negatively but significantly related with turnover intention. Hence, hypothesis (H6) was accepted. The R2 of the model is 0.223 which shows that approximately $22.3 \%$ of variance in the dependent variable that is turnover intention is explained by the mediating variable that is job satisfaction. The model is also significant with F-value of 49.284 as shown in Table 7.

Table7. Results -Dependent Variable: Turnover Intention

\begin{tabular}{lll}
\hline Variables & Co-efficient $(\beta)$ & P-value \\
\hline Constant & 17.535 & \\
Job Satisfaction & -.425 & .000 \\
F & 49.284 & .000 \\
R-square & .223 &
\end{tabular}

The equation 4 explores the mediating effect of job satisfaction between work life balance factors and the turnover intention of employees. The turnover intention was regressed on the work life balance factors and the job satisfaction. The relationship between the work life balance factors including workplace culture, social support, alternate working hours and turnover intention was insignificant except for the rewards and benefits when job satisfaction is added into the regression equation. According to Baron and Kenny equations, this result showed that the relation between the work life balance factors and turnover intention was partially mediated by job satisfaction. So, job satisfaction was examined as having a partial mediating effect between the work life balance factors and turnover intention. Thus, the hypothesis 7 was supported. Work life Balance factors including workplace culture (beta $=-.038, \mathrm{p}>0.05$ ) was negatively and insignificantly related to turnover intention. Similarly social support (beta $=-.074, \mathrm{p}>0.05)$ was negatively but insignificantly related with turnover intention. Similarly, alternate working hours (beta $=-.186, \mathrm{p}>0.05)$ and recreation $($ beta $=-.015$, 
$\mathrm{p}>0.05$ ) was insignificantly and negatively related to turnover intention. Lastly, rewards and benefits (beta $=$ $.196, \mathrm{p}<0.05$ ) and job satisfaction (beta $=-.404, \mathrm{p}<0.05$ ) was negatively but significantly related with turnover intention. The R2 of the model is 0.281 which shows that approximately $28.1 \%$ of variance in the dependent variable that is the turnover intention is explained by the combination of independent variables and mediating variable that includes workplace culture, social support, rewards and benefits, alternate working hours, recreation and job satisfaction among the employee's insurance companies. The model is also significant with F-value of 9.542 as shown in Table 8.

Table8. Results -Dependent Variable: Turnover Intention

\begin{tabular}{lll}
\hline Variables & Co-efficient $(\beta)$ & P-value \\
\hline Constant & 19.087 & \\
Workplace Culture & -.038 & .679 \\
Social Support & -.074 & .194 \\
Rewards \& Benefits & -.196 & .039 \\
Alternate Working Hours & -.186 & .302 \\
Recreation & -.015 & .930 \\
Job Satisfaction & -.404 & .000 \\
F & 9.542 & .000 \\
R-square & 0.281 & \\
& & \\
\hline
\end{tabular}

\section{Implications}

The top management and authorities of insurance companies have surely adapted some strategies to overcome the retention issues. The results of the current study have practical implications for the organizations who are interested in adopting different policies for retaining their employees in the near future. The findings of the current study suggested a model which provides flexibility in working hours along with allocation of more rewards and benefits. This will help the employees to balance their work and family life and make them satisfied with their job which in turn will reduce their turnover intentions. The benefits of adopting the different family friendly policies such as flexi-timings, employee assistance programs, and compressed work weeks are clear in business environment. A productive and healthy workforce is fundamental for them to struggle for the best talents and beside this; the organizations should also play an active role in developing the more encouraging work cultures on the implementation of policies. The results of the study might encourage the further applications of family friendly policies in different organizations to overcome the issue of job turnover.

\section{Limitations and Future Research}

There are various other factors of work life balance which can also be included such as motivation, relocation etc. Only one data collection method is used i-e the survey/questionnaire method in this study. The other data collection techniques can also be used with this research like interviews. The sample used in this study is restricted in context of geographical location because only Rawalpindi and Islamabad is chosen but other 
cities could be taken with large sample size to have more generalizability. The time constraint is always a big hurdle and limitation. The cooperation of employees was also a very big hurdle that was faced in this research. The response of employees was also very low because they were too busy in their own work and were not willing to participate effectively such policies (such as flexible schedules, childcare facilities and telecommunicating programs) to cater this employee retention problem. Finally, it is envisaged that this study will lead to increased awareness of retention process among top management and the need for further research in the subject area. This study only gives us a general idea that how the different factors related to work life balance affects the turnover intention through job satisfaction. Without the supportive workplace culture, the desired outcome of implementing the policies will be undermined. Even the different independent and mediating variables associated with turnover intention were used for regression analysis, the insights and explanations are limited for the support of the results of current study. Hence, to use regression approach for the further research is suggested in order to determine that which factors contributes to the great extent on the impact of work life balance factors, turnover intention and job satisfaction. The barriers to the execution of different family friendly policies are the most essential concerns for the upcoming research. Therefore, it is recommended that the impact of using job burnouts as mediators on job satisfaction and turnover intention should be explored in future research.

\section{Conclusion}

It can be concluded that this study highlighted the significant impact of work life balance factors on employee's turnover intention through job satisfaction. As due to nature of job and workload on employees working in insurance companies, the trend of promoting friendly workplace culture is not very remarkable. The results of this research showed that social support, alternate working hours and rewards and benefits were positively related with job satisfaction and negatively related with turnover intention. The findings of this study indicated that the relationship between rewards and benefits and turnover intention were partially mediated by the job satisfaction. This study might encourage and support the organizations to formulate effective policies for promoting social support and allocate rewards and benefits to its employees, which will help them to maintain balance between their work-life and might also reduce their turnover intentions.

\section{References}

Allen, T.D., 2011. Family-supportive work environments: the role of organizational perceptions, Journal of Vocational Behavior, 58, p. 414-35.

Buildings, J., 2005. What work in rewarding problem-solving teams? Compensation and Benefits Management, International Journal of Business and Social Science, 14(1), p. 55.

Claiborne, R., 2009. A Definition of Work life Balance, Retrieved from Helium.

Clark, A., Osward, A., \& Warr, P., 2007. Is job satisfaction U shaped?, Journal of Occupational and Organizational Psychology, 69, p. 57-81.

Dockel, A., Basson, J.S., \& Coetzee, M., 2006. The effect of retention factors on organizational commitment: An investigation of high technology employees. SA Journal of Human Resource Management, 4(2),p. 20-28.

Eikhof, D. R., Warhurst, C., \& Haunschild, A., 2007. Introduction what work? What life? What balance?, Journal of employee relations, 29(4), p. $325-333$.

Grover, S.L., \& Crooker, K.J.., 2005. Who appreciates family - responsive human resource policies: the impact of family - friendly policies on the organizational attachment of parents and non - parents, Personnel Psychology, 48(2), p. 271-288. 
Hartmann, A., 2008. A handbook of human resource management practice: Cambridge, UK:Kogen Page Limited.

Kuo, Y.F., \& Chen, L.S., 2004. Individual demographic differences and job satisfaction among Information Technology personnel: An empirical study in Taiwan. International Journal of Management, 21(2), p. 221-231.

Lambert, S.J., 2011. The link between work-life benefits and organizational citizenship behavior, Academy of Management Journal, 43, p. $801-815$.

Lindsey, L.C., \& Seesoms, K., 2006. Psychological Determinants of Leisure Time Physical Activity Participation among Public Universities in Malaysia, 2(2), 33-45.

Lockwood, N.R., 2003. Work/Life Balance: Challenges and Solution, Quarterly Report 2003, HR Magazine.

Lourel, M., Ford, M. T., Gamassou, C. E., Guéguen, N., \& Hartmann, A., 2008. Negative and positive spillover between work and home: Relationship to perceived stress and job satisfaction, Journal of Managerial Psychology, p. 438-449.

Malik, M.I., Gomez, S. F., Ahmed, M., \& Saif, M.I., 2010. Examining the relationship of work life balance, job satisfaction and turnover in Pakistan, International Journal of Sustainable Development, 2(1), p. 27-33.

Noor, K. M., 2011. Work-Life Balance and Intention to Leave among Academics in Malaysian, International Journal of Business and Social Science, 2(1).

Perlow, L.A., 2005. Putting the work back into work/family, Group and Organization Management, 20(2), p. $227-39$.

Rusell, G. \& L. Bowman., 2011.Work and family, current thinking, research and practice, Department of Family and Community Services, 45 , p. 45-89.

Santhi,T.S., Sundar, K., 2012. A Study on the work life balance of women employees in Information Technology industry, Zeinth Journal of Management, 6(1), p. 85-96.

Schwepker, S., 2004. Factors affection state government information technology employee turnover intentions, American Review of Public Administration, 35, p. 137-156.

Shaffer, M. A., Joplin, J.R.W., Bell, M. P., Lau, T., \& Oguz, C., 2011. Gender discrimination and job-related outcomes: A cross-cultural comparison of working women in the United States and China, Journal of Vocational Behavior, 57(3), p. $395-427$.

Shikdar, A.A., \& Das, B., 2003. A strategy for improving worker satisfaction and job attitudes in a repetitive industrial task: application of production standards and performance feedback, Journal of Ergonomics, 46(5), p. 466-481.

Silbert, L.T., 2005. The effect of Tangible Rewards on Perceived Organizational Support. Management Sciences, International Journal of Management and sciences, 14(1).

Silverthrone, J. M., 2008. Work-family conflict and turnover intention: Exploring the Moderation effects of perceived work-family support. New Zealand Journal of Psychology, 33(1), p. 35-39.

Spector, P.E., 2007. Job Satisfaction: Application, Assessment, Causes and Consequences: Advanced Topics in Organizational Behavior, Sage, London

Tabachnick, B.G., \& Fidell, L.S., 2011. In: Using Multivariate Statistics. (5 th ed). Boston: Pearson Education Inc.

Uma, S. (2010). A Study on the relationship between Work life Balance and Job Satisfaction, Rajagiri College of University Science, 25, 88.

Valcour, M., Ollier-Malaterre, A., Matz-Costa, C., Pitt-Catsouphes, M., \& Brown, M., 2011. Influences on employee perceptions of organizational work-life support: Signals and resources. Journal of Vocational Behavior, 79, p. 588-595.

Williams, E.S., Konrad, T.R., Linzer, M., McMurray, J., Pathman, D.E., Gerrity, M., Schwartz, M.K., Scheckler, W.E., Van Kirk, J., 
